\title{
Incidence and predictors of severe obstetric morbidity in a teaching hospital
}

\section{Bajagain R', Saha $\mathbf{R}^{2}$}

${ }^{1}$ Rupa Bajagain, Resident; ${ }^{2}$ Rachana Saha, Professor; Department of Obstetrics and Gynaecology, Kathmandu Medical College, Kathmandu, Nepal

\begin{abstract}
Background: Evaluation of severe obstetric morbidity is an important aspect of optimum maternal health. Towards this, the Waterstone and Mantel criteria have been used to know the incidence, predictors and causes of severe obstetric morbidity.

Objectives: The study aimed to estimate incidence, predictors and causes of obstetric morbidity at Kathmandu Medical College and Teaching Hospital.

Methods: A hospital-based prospective study was carried out from $1^{\text {st }}$ September 2014 to $31^{\text {st }}$ August 2015 . All cases of severe obstetric morbidity according to the Mantel and Waterstone criteria were identified. The socio-demographic and healthcare characteristics of extremely severe cases were compared with controls which included women who were admitted before and after the indexed cases.

Results: There were 2270 deliveries during the study period, out of which 74 cases of severe obstetric morbidities were identified i.e. an incidence of 32.5 per 1000 deliveries. During the study period, there were three maternal deaths attributed to conditions studied. Disease-specific morbidities per 1000 deliveries were 18.9 for haemorrhage, 9.2 for severe pre-eclampsia, 0.88 for eclampsia, 0.44 for haemolysis elevated liver enzyme and low platelet count and 3.08 for sepsis. A total of 26 patients were admitted in Intensive care unit which was 1.145 per 100 of total deliveries.

Conclusion: Severe obstetric morbidity and its relation to mortality may be more sensitive measures of pregnancy outcome than mortality alone. In this study, most events are related to obstetric haemorrhage and severe pre-eclampsia.
\end{abstract}

Key words: Eclampsia, Intensive care unit, Obstetric morbidity, Postpartum haemorrhage

\section{INTRODUCTION}

W orld Health Organization (WHO) estimated that there were more than 500,000 maternal deaths worldwide in 2005, of which, $95 \%$ occurred in developing countries ${ }^{1}$. Maternal mortality has been used as a measure of the success of obstetric intervention but at present, it is too rare for use in local practice in the developed world ${ }^{2}$. In view of inadequate qualitative and quantitative data on maternal mortality and decreasing maternal mortality rates, new indicators have been developed to evaluate maternal health issues more effectively ${ }^{3}$. Severe obstetric morbidity is a newly described condition that has been investigated for the last 20 years. There have been several studies on

Address for correspondence

\section{Dr. Rupa Bajagain}

Resident, Department of Obstetrics and Gynecology

Kathmandu Medical College Teaching Hospital

Sinamangal, Kathmandu, Nepal obstetric morbidity both in developing and developed countries and the spectrum of its causes overlaps to that of obstetric mortality, especially hypertensive conditions and hemorrhage ${ }^{4}$. Although it is a highly relevant issue, it has been scarcely investigated. Most studies have used Mantel and Waterstone criteria ${ }^{5}$. Obstetric morbidity is gaining interest as a new indicator of the quality of obstetric care. In view of inadequate data in our setting, this study is undertaken to know the incidence, predictors and causes of severe obstetric morbidity encountered at Kathmandu Medical College and Teaching Hospital (KMCTH).

\section{METHODS}

A hospital based descriptive observational study was conducted in the Department of Obstetrics and Gynaecology, KMCTH from $1^{\text {st }}$ September 2014 to $30^{\text {th }}$ August 2015. KMCTH is a 750 bedded tertiary care hospital which includes maternity ward, surgery centre, 
adult and neonatal Intensive Care Unit (ICU). Disease specific criteria as described by Waterstone and Mantel were enrolled in the study 5 . Six specific disease groups are given in the box:

\section{EXCLUSION CRITERIA}

1. Haemodynamically stable patients with haemorrhage not requiring resuscitation or acute blood transfusion.

2. Patients with stable cardiac or respiratory disease not requiring ICU admission.

\section{Definition of severe obstetric morbidity}

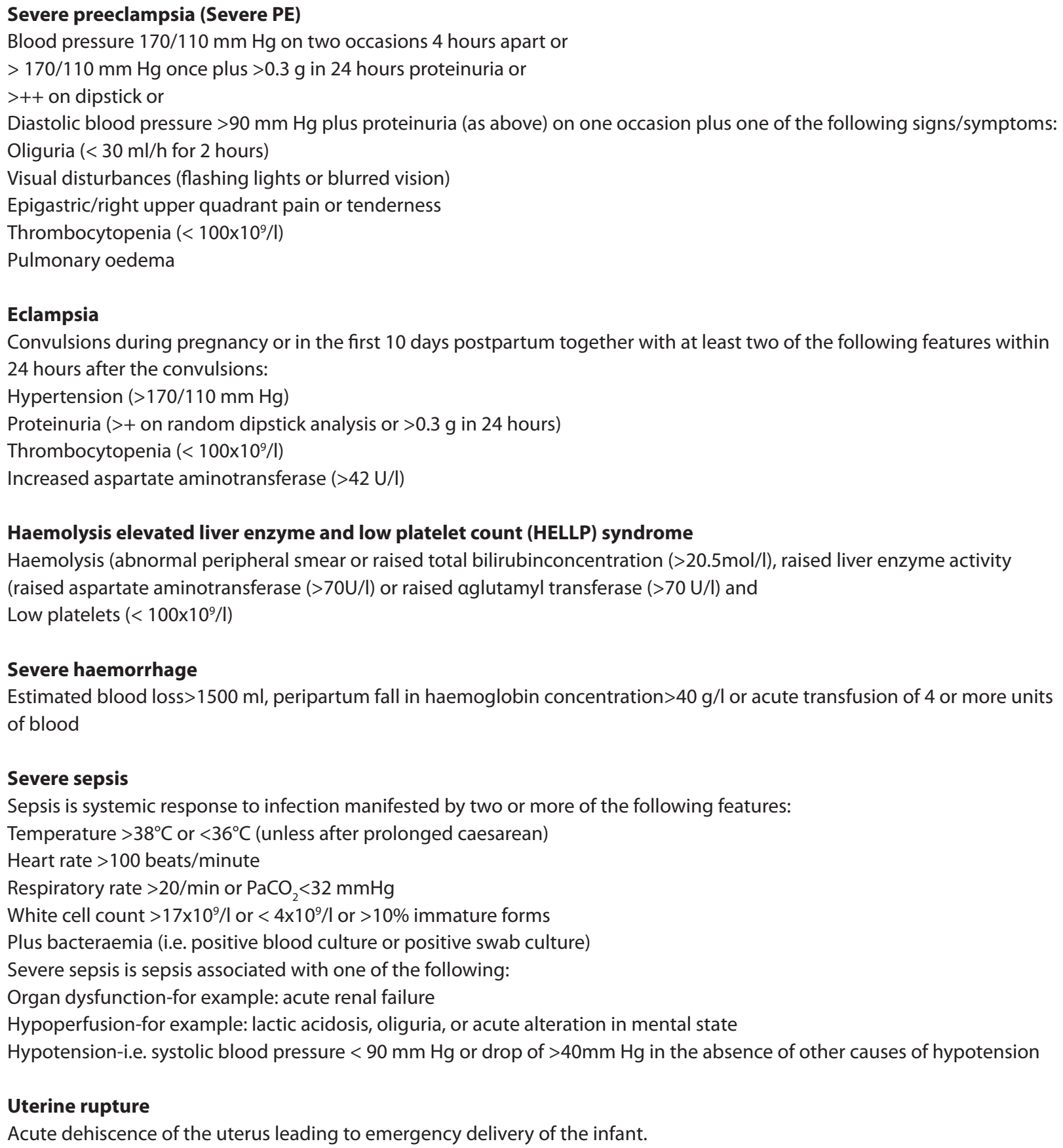


All cases of severe obstetric morbidities as defined by Mantel and Waterstone criteria were taken from admission and delivery records. Patient characteristics such as age, parity, antenatal care, co-morbidities, mode of delivery and details of disease-specific conditions and their management were recorded. Data retrieved included age, parity, co-morbidity and mode of delivery. Risk factors like age, parity, previous co-morbidities and mode of delivery were assessed by comparing the cases and controls. Control included women who got admitted before and after the indexed case. Data was entered into computer through Statistical Package for Social Sciences (SPSS) version 20 and was analysed by descriptive statistics. The quantitative variables are presented as mean \pm standard deviation (SD). P value $<$ 0.05 is taken as significant.

\section{RESULTS}

There were 2270 deliveries during the study period. The mean age of women in the study was $28.50 \pm 5.36$ years. Most of them were primigravida.

Seventy four cases were identified as having severe obstetric morbidities i.e. an incidence of 32.5 per 1000 deliveries. During the study period, there were three maternal deaths attributed to conditions studied (one from haemorrhage, two from sepsis). Table 1 shows the incidence of severeobstetric morbidity by condition diagnosed. Haemorrhage was the most common cause of obstetric morbidity. Predictors of obstetric morbidity are shown in Table 2. The mean gestational age, lower segment caesarean section and associated co-morbid condition like previous history of postpartum haemorrhage (PPH) varied significantly.

Table 1: Severe acute obstetric morbidity by clinical conditions

\begin{tabular}{lcc}
\hline Category of morbidity & Frequency & Percent \\
\hline Obstetric Haemorrhage* & 43 & 58.1 \\
\hline PPH & 32 & 43.2 \\
\hline Incomplete abortion & 6 & 8.1 \\
\hline Ruptured ectopic & 5 & 6.7 \\
\hline Hypertensive disorder of Pregnancy & 24 & 32.4 \\
\hline Severe PE & 21 & 28.3 \\
Eclampsia & 2 & 2.7 \\
HELLP & 1 & 1.3 \\
\hline Sepsis & 7 & 9.5 \\
\hline Total & $\mathbf{7 4}$ & $\mathbf{1 0 0 . 0}$ \\
\hline
\end{tabular}

*12 cases needed transfusion of $\geq 4$ pint blood

HELLP syndrome: Haemolysis elevated liver enzymes and low platelet; PPH: Postpartum haemorrhage; PE: Pre-eclampsia

Table 2: Comparison of predictors in cases of severe obstetric morbidity and controls

\begin{tabular}{|c|c|c|c|c|c|}
\hline \multirow{2}{*}{ Characteristics } & \multicolumn{2}{|c|}{ Cases $(n=74)$} & \multicolumn{2}{|c|}{ Controls ( $n=148$ ) } & \multirow[t]{2}{*}{ p-value } \\
\hline & Mean & SD & Mean & SD & \\
\hline Age (years) & 28.50 & 5.36 & 27.28 & 5.55 & 0.816 \\
\hline Parity & 1.53 & 0.65 & 1.42 & 0.5 & 0.328 \\
\hline Gestational age (weeks) & 35.28 & 4.6 & 39.04 & 1.7 & $<0.001$ \\
\hline \multicolumn{6}{|l|}{ Mode of delivery } \\
\hline & Frequency & Percent & Frequency & Percent & \\
\hline $\begin{array}{l}\text { Lower segment caesarean } \\
\text { section }\end{array}$ & 35 & 47.2 & 45 & 30.4 & \multirow[t]{2}{*}{0.026} \\
\hline Normal Delivery & 25 & 33.7 & 76 & 51.3 & \\
\hline \multicolumn{6}{|l|}{ Co-morbidities } \\
\hline Hypertension & 18 & 24.3 & 14 & 9.45 & 0.003 \\
\hline Gestational Diabetes Mellitus & 6 & 8.1 & 6 & 4.05 & 0.208 \\
\hline Cardiac disease & 1 & 1.3 & 0 & 0 & 0.156 \\
\hline Previous history of PPH & 2 & 2.7 & 0 & 0 & 0.045 \\
\hline
\end{tabular}




\section{DISCUSSION}

This study found the incidence of severe obstetric morbidity to be 32.5 per 1000 live births. The finding is consistent with those reported in the literature, 0.7 to 101.7 cases per 1000 births $^{6}$. Souza et al found a severe maternal morbidity rate of 15 to 42 cases per 1000 births $^{4}$. Luz et al found the rate of severe morbidity of 44.9 per 1000 live births ${ }^{7}$. Mantel et al showed maternal mortality rate of $20 \%$ which is consistent with data from our study using the same criteria ${ }^{8}$. These data corroborate evidence reported in the literature ${ }^{9}$. Fillip et al in a study in Africa identified haemorrhage and hypertensive disorders of pregnancy as the most common condition of obstetric morbidity ${ }^{10}$.In this study the most common cause of obstetric morbidity was obstetric haemorrhage $(58.1 \%)$ which occurred in 43 women as identified by Waterstone criteria ${ }^{11}$. The second common cause is hypertensive disorder of pregnancy (32.4\%). Similar results were observed in a study done at our hospital in 2010 where haemorrhage $(41.66 \%)$ was the commonest cause of obstetric near miss ${ }^{14}$. Likewise in a big multicentre study done in Nepal by Rana et al, $\mathrm{PPH}(40 \%)$ was the commonest cause of maternal near miss followed by hypertensive disorder ${ }^{15}$.

The main predictors of severe obstetric morbidity in this study were gestational age, associated morbidities like hypertension, diabetes mellitus, previous history of PPH and emergency caesarean section. The main indications for caesarean section were severe pre-eclampsia and eclampsia resulting into haemorrhage. Duration of hospital stay was prolonged in cases as compared to control group. These predictors are amenable to change with obstetric intervention like reducing the rapidly rising rate of caesarean section.

Twenty six patients were admitted to the ICU. This gives the incidence of $1.14 \%$ of all deliveries during the study period, which was low compared to a study done in one of the largest maternity hospital of Nepal which showed an ICU admission rate of $2.3 \%$ of all deliveries ${ }^{12}$. The major indications for ICU admission were hypertensive disorder and obstetric haemorrhage ${ }^{13}$. Three mortalities were noted during the study period among the admitted patients. One death was due to sepsis leading to multi organ failure. The second case was from direct complication of delivery and PPH. The third mortality was also from multi organ failure which was a case of infective hepatitis $E$ in a pregnant patient. There were two cases of Caesarean hysterectomy during the study.

\section{CONCLUSION}

This study concludes that the incidence of severe obstetric morbidity is 32.5 per 1000 live births. Haemorrhage being the most common cause of obstetric morbidity followed by hypertensive disorder and caesarean section were found to increase the risk of morbidity. Development and evaluation of ways of predicting and reducing risk are required for the management of haemorrhage and pre-eclampsia.

\section{REFERENCES}

1. World Health Organization. World Health Statistics: World Health Organization, Geneva; 2009.

2. Department of Health. Why mothers die. Report on confidential enquiry into maternal deaths in UK.1994-1996.

3. Morse MC, Fonseca S, Gottgtroy C. Severe maternal morbidity and near miss in a regional reference hospital. RevistaBrasileire de epidemiologia. 2011;14.

4. Souza JP, Cecatti JG, Parpinelli MA, Serruya SJ, Amaral E. Appropriate criteria for identification of near-miss maternal morbidity in tertiary care facilities: a cross sectional study. BMC Pregnancy Childbirth.2007;11(7):20.

5. Stones W, Lim W, Al-Azzawi F, Kelly M. An investigation of maternal morbidity with identification of life-threatening near miss episodes. Health Trends.1991;23:13-5.

6. Minkauskiene M, Nadisauskiene R, Padaiga Z, Makari S. Systematic review on the incidence and prevalence of severe maternal morbidity. Medicina (Kaunas).2004;40:299-309.

7. Luz AG, Tiago DB, Silva JC, Amaral E. Severe maternal morbidity at a local reference university hospital in Campinas, São Paulo, Brazil. Rev Bras Ginecol Obstet.2008;30(6):281-6.

8. Mantel GD, Buchmann E, Rees $H$, Pattinson RC. Severe acute maternal morbidity: a pilot study of a definition for a near-miss. $\mathrm{Br} J$ ObstetGynaecol.1998;105(9):985-90.

9. Say L, Pattinson RC, Gülmezoglu AM. WHO systematic review of maternal morbidity and mortality: the prevalence of severe acute maternal morbidity (near miss). Reprod Health.2004.

10. Filippi V, Ronsmans C, Gohou V, Goufodji S, Lardi M, Sahel A et al. Maternity wards or emergency obstetric 
rooms? Incidence of near miss events in African hospitals.ActaObstetGynecol Scand.2005;84(1):11-6.

11. Waterstone $M$, BewleyS, Wolfe C. Incidence and predictor of severe obstetric morbidity: case control study.BMJ. 2001;322:1089-94.

12. Upadhyaya I,Chaudhary P. Severe maternal morbidity and intensive care in Paropakar Maternity and WomensHospital.Nep J ObstetGynaecol.2013 Jul-Dec;8(2):38-41.
13. Saha R, Shakya A. Study of obstetric patients admitted to Intensive Care Unit at Kathmandu Medical College Teaching Hospital.JKMC. 2013 Oct-Dec;2(6):196-200.

14. Shrestha NS, Saha R, Karki C. Near miss maternal morbidity and maternal mortality at Kathmandu Medical College Teaching Hospital. Kathmandu Univ Med J. 2010;8:222-6.

15. Rana A, Baral G, Dangal G. Maternal near-miss: a multicenter surveillance in Kathmandu valley. J Nepal Med Assoc. 2013;52:299-304. 